\title{
DETERMINATION OF RESIDUAL DIMETHYL SULFATE IN METHOXSALEN DRUG SUBSTANCE BY PRE-COLUMN DERIVATIZATION WITH STATIC HEADSPACE GAS CHROMATOGRAPHY
}

\author{
AJIT ANERAO*, BHUSHAN PATIL, NITIN PRADHAN \\ $R$ and D centre (API), Wanbury Ltd., EL-16, TTC Industrial Estate, Mahape, Navi Mumbai 400710, India \\ Email: ajit.anerao@wanbury.com
}

Received: 01 Jun 2018 Revised and Accepted: 12 Jul 2018

\section{ABSTRACT}

Objective: Dimethyl sulfate has been highlighted as potential genotoxic and carcinogenic impurity. A sensitive Headspace gas chromatography (HSGC) method with pre-column derivatization was developed and validated for the determination of dimethyl sulfate impurity in methoxsalen active pharmaceutical ingredient.

Methods: HS-GC method on the column Agilent DB-5, 30m X $0.53 \mathrm{~mm}$, film thickness $1.5 \mu \mathrm{m}$, with flame ionization detector (FID) was used. Derivatization reagent concentration, time of reaction and $\mathrm{pH}$ of the solution were optimized during method development. This analytical method was evaluated by performing method validation as per ICH guideline.

Results: The proposed method was specific, linear, accurate, rugged and precise. The calibration curves showed good linearity over the concentration range of $0.5 \mu \mathrm{g} / \mathrm{ml}$ to $3.0 \mu \mathrm{g} / \mathrm{ml}$ and the correlation coefficient was 0.999 . Method had very low limit of detection (LOD) and limit of quantification (LOQ) $2.0 \mu \mathrm{g} / \mathrm{g}$ and $5.0 \mu \mathrm{g} / \mathrm{g}$ respectively. Accuracy was observed within $98.1 \%-104.5 \%$.

Conclusion: The developed method was demonstrated to be accurate, robust and sensitive for the determination of dimethyl sulfate impurity in methoxsalen drug substance.

Keywords: Methoxsalen, Dimethyl sulfate, GC-HS, Derivatization, Validation

(c) 2018 The Authors. Published by Innovare Academic Sciences Pvt Ltd. This is an open access article under the CC BY license (http://creativecommons.org/licenses/by/4.0/) DOI: http://dx.doi.org/10.22159/ijpps.2018v10i8.27670

\section{INTRODUCTION}

Methoxsalen is a naturally occurring photoactive substance found in the seeds of the Ammi majus (Umbelliferae) plant. It belongs to a group of compounds known as psoralens or furocoumarins [1]. The chemical name of methoxsalen is 9-methoxy-7H-furo [3,2-g] [1]benzopyran7-one. It has an empirical formula of $\mathrm{C}_{12} \mathrm{H}_{8} \mathrm{O}_{4}$ and a molecular weight of $216.19 \mathrm{~g} \mathrm{~mole}^{-1}$ [2]. Photochemotherapy (PUVA) is treatment involving the use of psoralen, like methoxsalen, an exogenous photosensitizer followed by ultraviolet A (UVA) irradiation [3-5].

The manufacturing process of methoxsalen is seven step syntheses. In synthetic stage five a key raw material dimethyl sulfate (DMS) is used as methylating agent. It is used mainly for converting activehydrogen compounds such as phenols, amines and thiols to the corresponding methyl derivatives. Dimethyl sulfate is probably carcinogenic to humans so IARC classified DMS in Group 2A. It is a potent genotoxic chemical which can directly alkylate DNA both in vitro and in vivo [6-8]. Because of the known carcinogenicity and genotoxicity, the presence of residual dimethyl sulfate in methoxsalen drug substance must be controlled as per European Medicines Agency (EMA), International Conference on Harmonization [9] and Food and Drug Administration (FDA) guidelines $[10,11]$. EMA and FDA guidelines proposed the use of the "threshold of toxicological concern" (TTC) concept for the limit of genotoxic/carcinogenic impurities. The concentration limit, in ppm, of genotoxic impurity in drug substance, is the ratio of TTC in $\mu \mathrm{g}$ per day to the expected dose of drug substance in a gram per day. Considering the recommended daily maximum dose of $0.070 \mathrm{~g}$ methoxsalen per day $[1,12]$, dimethyl sulfate must be limited to less than $21.4 \mu \mathrm{g} / \mathrm{g}$ in drug substance. So it is necessary to develop sensitive, accurate and robust analytical method.

Methoxsalen is official drug substance in United State Pharmacopoeia (USP). Dimethyl sulphate is not controlled in the USP monograph [2]. During literature survey several analytical methods are found reported of estimation of dimethyl sulfate. Dimethyl sulfate is checked at workplace atmosphere by GC with electrolytic conductivity detector (sulphur mode) at trace level using stainless steel Chromosorb WHP column [13]. DMS is estimated at workplace atmosphere by thin layer chromatography (TLC) method derivatizing with 4-nitrophenol. The LOQ of DMS is reported $40 \mathrm{ppm}$ which is very high because TLC technique has limitations in sensitivity point of view [14]. Quantification of dimethyl sulfate by GCMS is reported by derivatizing with pentafluorobenzenethiol. This report suggests that solution stability and diluent study need to be optimized and mass detector is necessary to get DMS sensitivity at trace level [15]. Few more methods are reported by extracting the DMS in a solvent and tested by GC-MS [16-20]. DMS quantification by ion chromatography technique with conductivity detector is also reported by separating ionic compounds using Allsep anion exchange column [21]. Literature suggests that to achieve such a low level of limit of quantification hyphenated techniques with sophisticated instruments like GC-MS or sulphur specific detector or LC with conductivity detector is required. It might hardly possible for quality control laboratory of pharmaceutical industry to perform the testing routinely with GC-MS because of the cost and maintenance of a mass detector is very high. So in present research, analytical method is developed to quantify the DMS in methoxsalen drug substance with flame ionization detector. Due to low sensitivity of FID, pre-column derivatization was tried to achieve the quantification of analyte at trace level. The proposed analytical method was validated as per International conference on harmonization guidelines ICH Q2-R1 [22].

\section{MATERIALS AND METHODS}

\section{Method of analysis}

\section{Instrumentation}

Perkin Clarus-500 GC with headspace auto sampler and flame ionization detector (FID) using Total Chrome Navigator software. Refer chromatographic parameters as per given in table 1. 
Table 1: Chromatography parameter

\begin{tabular}{|c|c|}
\hline Column & DB-5, 30m X 0.53 mm, Film Thickness: $1.5 \mu \mathrm{m}$ \\
\hline Oven Temperature & $40^{\circ} \mathrm{C}$ \\
\hline Oven Program & $\begin{array}{l}40{ }^{\circ} \mathrm{C} \text { hold for } 8.0 \mathrm{~min} \text {, ramp- } 1 \text { at } 5^{\circ} \mathrm{C} / \mathrm{min} \text { to } 100^{\circ} \mathrm{C} \text { hold for } 0 \text { minute, ramp- } 2 \text { at } 20^{\circ} \mathrm{C} / \mathrm{min} \text { to } 250^{\circ} \mathrm{C} \\
\text { hold for } 5 \text { minute, }\end{array}$ \\
\hline Detector & Flame Ionization Detector (FID) \\
\hline Detector temperature & $280^{\circ} \mathrm{C}$ \\
\hline Injector temperature & $220^{\circ} \mathrm{C}$ \\
\hline Carrier Gas & Nitrogen \\
\hline Carrier Gas pressure & 5.0 psi \\
\hline Run Time & $32.50 \mathrm{~min}$ \\
\hline \multicolumn{2}{|l|}{ Headspace Conditions } \\
\hline Oven Temperature & $90^{\circ} \mathrm{C}$ \\
\hline Sample Line Temperature & $110^{\circ} \mathrm{C}$ \\
\hline Transfer line Temp & $120^{\circ} \mathrm{C}$ \\
\hline Headspace Pressure & 16 psi \\
\hline Pressurize time & $3.0 \mathrm{~min}$ \\
\hline Inject time & $0.20 \mathrm{~min}$ \\
\hline Withdraw time & $0.5 \mathrm{~min}$ \\
\hline Thermostat time & $30.0 \mathrm{~min}$ \\
\hline GC Cycle Time & $46.0 \mathrm{~min}$ \\
\hline
\end{tabular}

\section{Chemical and reagents}

GC columns used of Agilent DB-5 of a dimension 30 meters, internal diameter $0.53 \mathrm{~mm}$ with film thickness $1.5 \mu \mathrm{m}$. Agilent DB-1 of a dimension 30 meters, internal diameter $0.53 \mathrm{~mm}$ with film thickness $3 \mu \mathrm{m}$. Agilent DB-624 of a dimension 30 meters, internal diameter $0.53 \mathrm{~mm}$ with film thickness $3 \mu \mathrm{m}$. Anisole standard was procured from AVRA synthesis of purity $99.5 \%$, dimethyl sulfate from Finar Ltd. of purity $99.0 \%$, dimethyl sulfoxide from Rankem, phenol from Rankem, sodium hydroxide from Merck and purified HPLC grade water was used in the experimentation.

\section{Solution preparation}

Diluent preparation: Accurately weighed and transferred $10.7 \mathrm{~g}$ of phenol and $5.0 \mathrm{~g}$ of sodium hydroxide into $500 \mathrm{ml}$ volumetric flask and diluted up to the mark with premixed dimethyl sulfoxide: Water $(1: 1 \mathrm{v} / \mathrm{v})$ mixture. It was sonicated for two minutes; shake for one minute again sonicated for two minutes. This solution is used as diluent for preparation of blank, standard solution and test solution.

Standard stock solution A: Accurately weighed and transferred $0.10 \mathrm{~g}$ of dimethyl sulfate standard into $100 \mathrm{ml}$ volumetric flask containing $40 \mathrm{ml}$ of diluent and diluted up to the mark with diluent, shake it for two minutes again sonicated for five minutes.

Note: 1) Diluent should be ready before weighing of dimethyl sulfate standard.

2) After transfer of dimethyl sulfate standard to $100 \mathrm{ml}$ volumetric flask immediately dilute up to the mark with diluent.

Standard stock solution B: Accurately transferred $1.0 \mathrm{ml}$ of standard stock solution A in to $100 \mathrm{ml}$ volumetric flask, added diluent and diluted up to the mark with diluent. Shake and mix well.

Standard stock solution C: Accurately transferred $5.0 \mathrm{ml}$ of standard stock solution B in to $25 \mathrm{ml}$ volumetric flask, added diluent and diluted up to the mark with diluent. Shake and mix well.

Blank preparation: In to a $20 \mathrm{ml}$ GCHS vial added $2.0 \mathrm{ml}$ of diluent and crimped the head space vial with septa, star spring and alumina cap.

Standard solution: In to a $20 \mathrm{ml}$ GCHS vial added $2.0 \mathrm{ml}$ standard stock solution $C$ and crimped the headspace vial with septa, star spring and alumina cap.

Test preparation: Accurately weighed and transferred $0.2 \mathrm{~g}$ of a sample in to a $20 \mathrm{ml}$ GCHS vial and added $2.0 \mathrm{ml}$ of diluent and crimped the headspace vial with septa, star spring and alumina cap.

\section{Procedure}

Performed blank followed by standard solution six times, blank followed by two test preparations. Run the chromatograph for 32.5 min and record the chromatogram. The retention time of dimethyl sulfate derivative i.e. anisole is $15.0 \mathrm{~min}$.

\section{Acceptance criteria for system suitability}

$\%$ RSD of area of dimethyl sulfate peak in six replicate injections should not be more than 15.0 .

\section{CALCULATION}

Calculated the content of dimethyl sulfate in ppm by formula given below

(peak area of DMS in sample-peak area DMS in blank) $\times$ Conc. of std. in $\mathrm{mg} / \mathrm{ml} \times \mathrm{P} \times 10^{6}$

(Avg. peak area of DMS in std.-peak area of DMS in blank) $\times$ Conc. of sample in $\mathrm{mg} / \mathrm{ml} \times 100$

\section{RESULTS}

\section{Analytical method development}

Dimethyl sulfate is a volatile compound of boiling point $18^{\circ} \mathrm{E}$ and has no chromophores. For analysis of such a ultr-violet (UV) inactive volatile compound gas chromatography (GC) is a suitable technology. To quantify the analyte at parts per million (ppm) levels, the concentration of test solution is required more. If the large quantity of test solution is injected on GC column it may spoil in long term usage so head space technique is preferable over liquid injection. Sensitivity of flame ionization detector is not sufficient to detect dimethyl sulphate at such a low concentration. So to enhance the response of dimethyl sulphate it was decided to perform precolumn derivatization technique. Considering all above properties of the compound and purpose of the requirement of method development, GC headspace pre-column derivatization method is developed with FID after optimizing chromatographic parameters. Methylation of phenol with DMS in presence of sodium hydroxide is reported in literature [23]. The derivatized complex of dimethyl sulphate and phenol is anisole which has considerable and sufficient response with FID. It has been reported that DMS can be degraded with sodium hydroxide solution (1 mol/l), sodium carbonate solution ( $1 \mathrm{~mol} / \mathrm{l})$, or ammonium hydroxide solution $(1.5 \mathrm{~mol} / \mathrm{l})$. Complete destruction of undiluted DMS or DMS in solvents miscible with water (methanol, ethanol, dimethyl sulfoxide, dimethyl formamide, acetone) or solvents partially miscible or immiscible with water (toluene, p-xylene, benzene, 1-pentanol, ethyl acetate, chloroform, carbon tetrachloride, acetonitrile) [24]. So many attempts were made to stabilize the DMS in various solvents but it is observed that further after derivatization the area of anisole was found inconsistent and reducing gradually. The derivatization reaction mechanism is explained in fig. 1. 
<smiles>Oc1ccccc1</smiles>

$\mathrm{NaOH}$

phenol<smiles>[AlH2]Oc1ccccc1</smiles>

sodium phenoxide<smiles>[AlH2]Oc1ccccc1</smiles>

sodium phenoxide<smiles>COc1ccccc1</smiles>

anisole
Fig. 1: Derivatization reaction mechanism and formation of anisole

This is two step reactions and it gets complete at room temperature. Once the sodium phenoxide is formed it is found stable. So first sodium phenoxide is prepared by addition of phenol and sodium hydroxide at room temperature in aqueous dimethyl sulfoxide solution. This solution is used as a reagent blank, for preparation of DMS standard and test solution. After optimization of these steps the anisole derivative was found stable in solution form and further the method is found satisfying all validation parameters like linearity, solution stability and accuracy. Anisole reference standard was procured from Avra Synthesis and injected in proposed method of analysis. The retention time of anisole standard and derivatized dimethyl sulfate standard peaks are eluting exactly at same retention time $15.0 \mathrm{~min}$. During method optimization various stationary phases of different polarity were used like DB-624 (6\% cyanopropyl phenyl and 94\% dimethylpolysiloxane), DB-1 (100\% dimethylpolysiloxane) and DB-5 (5\% diphenyl and 95\% dimethylpolysiloxane). In DB-624 DMS was eluting very close to DMSO peak and with DB-1 column DMS peak tailing factor was more than 2.0. DB-5 column was selected because DMS peak was separated from DMSO with resolution more than 5.0 and peak was symmetrical.

\section{Analytical method validation \\ Selectivity}

Selectivity is the ability of the method to determine accurately and specifically the analyte of interest in the presence of other components in a sample matrix that may be expected to be present in the sample matrix under the stated conditions. Selectivity of the method was evidenced by comparing blank, dimethyl sulfate, methoxsalen and all specified impurities separate injections. There is no interfering peak at the retention time of dimethyl sulfate is observed. Dimethyl sulfate is well resolved from all other specified solvent peaks which are used in the manufacturing process of methoxsalen. Selectivity of methanol, acetone, methylene chloride, n-hexane, ethyl acetate, toluene and benzene had been checked and found separated from dimethyl sulfate peak. Refer figure- 2 and 3 of dimethyl sulfate standard solution and test solution chromatograms.

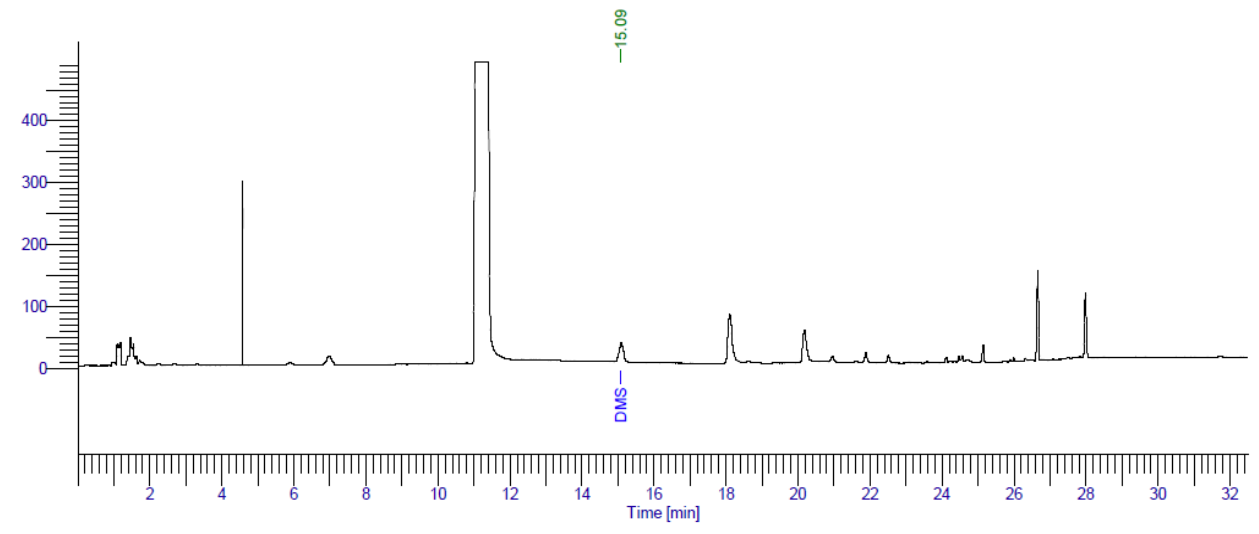

Fig. 2: Dimethyl sulfate standard solution chromatogram

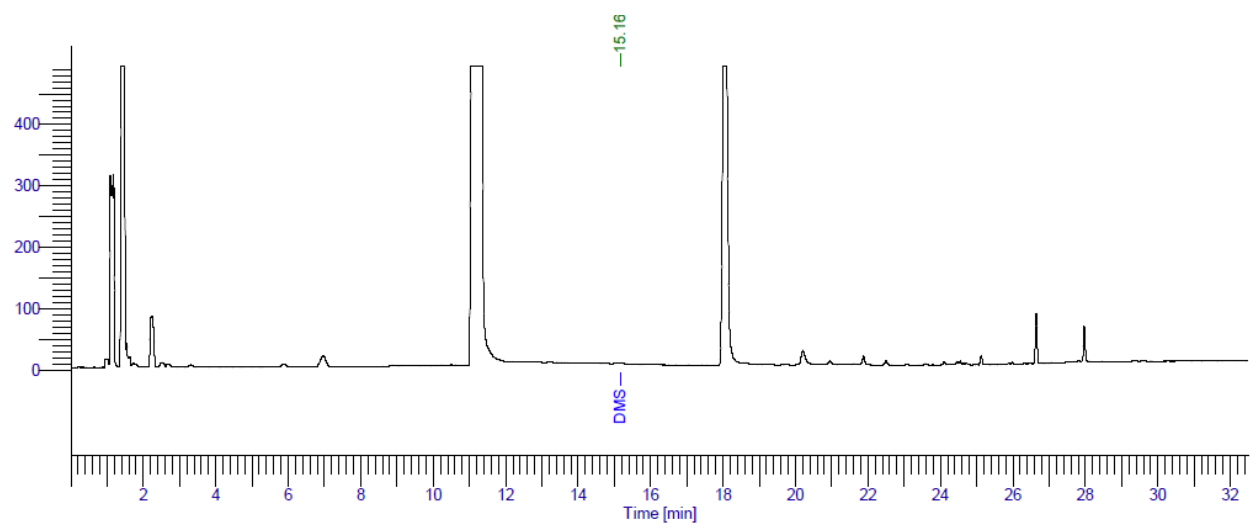

Fig. 3: Test solution chromatogram of methoxsalen

\section{Solution stability}

Drug stability in the active pharmaceutical ingredients (API) is a function of storage conditions and chemical properties of the drug and its impurities. The solution stability till twenty-six hours of derivatized DMS had been checked by injecting standard solution.
DMS standard solution was prepared fresh before injection and immediately injected and same solution was injected after twentysix hours. The peak area of DMS of freshly prepared standard solution was observed 280527 and after twenty six hours it was 272834. No significant change in area was observed after twenty-six hours. 


\section{LOD and LOQ}

The limit of detection (LOD) is the lowest concentration of the analyte in a sample that can be detected but not necessary quantified. The obtained LOD values of specified impurities and API is discussed.

LOD $=3.3 \times \sigma / \mathrm{S}$

The limit of quantitation (LOQ) is the lowest concentration or amount of the analyte that can be determined quantitatively within an acceptable level of repeatability precision and trueness.

\section{$\mathrm{LOQ}=10.0 \times \sigma / \mathrm{S}$}

Where $\sigma=$ the standard deviation of the response and $S=$ slope of the calibration curve
LOD and LOQ concentration are reported in parts per million (ppm) with respect to methoxsalen test concentration. LOD is $2.0 \mathrm{ppm}$ and LOQ is $5.0 \mathrm{ppm}$. Precision of LOQ is checked by injecting six replicate injections. Relative standard deviation (RSD) of peak area of dimethyl sulfate at LOQ level was observed 5.4\% which proves consistency and reproducibility of the method at trace level.

\section{Linearity}

Under the experimental conditions, the peak area vs. concentration plot for the proposed method was found to be linear over the range of LOQ level i.e. $25 \%, 50 \%, 100 \%$, and $150 \%$ of the specified limit with a regression coefficient is 0.999 . The regression coefficient $\left(\mathrm{r}^{2}\right)$ is more than 0.99 is generally considered as evidence of acceptable fit of the data to the regression line. Linearity plot is given in fig. 4 .

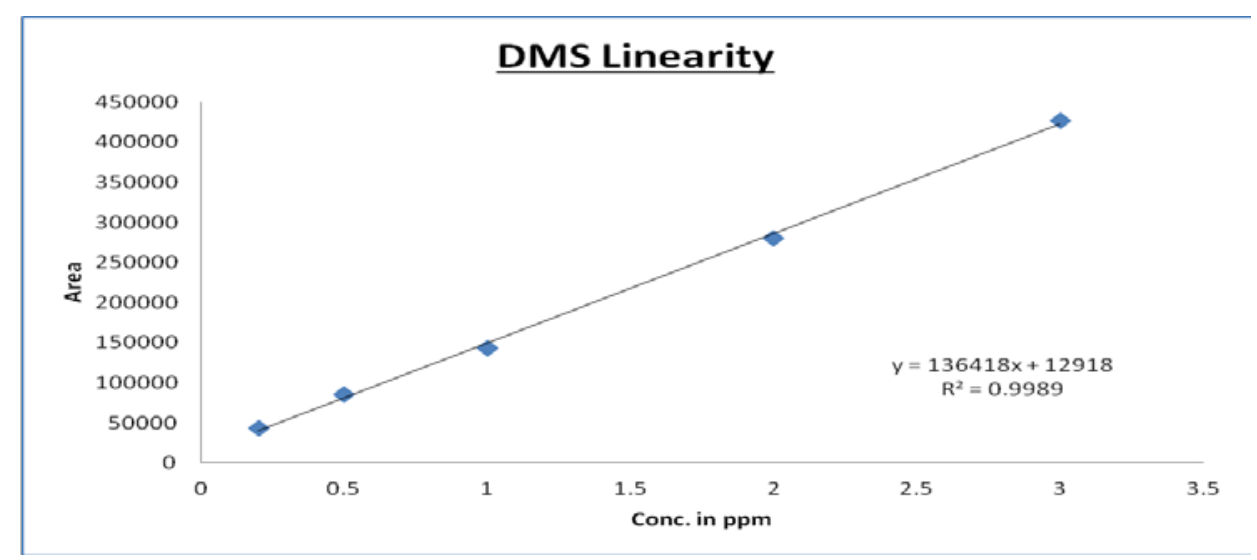

Fig. 4: Linearity plot of dimethyl sulfate derivative

\section{Accuracy}

Accuracy can be defined as the closeness of agreement between a test result and the accepted reference value. Accuracy of the method was determined by recovery study. Analytical method may be considered validated in terms of accuracy if the mean value is within $\pm 20 \%$ of the actual value. During recovery study methoxsalen API batch was analyzed and then dimethyl sulfate is spiked in the API at LOQ level, $100 \%$ and $150 \%$ with respect to the limit of dimethyl sulfate that is $21.4 \mathrm{ppm}$. The recovery was found $104.5 \%, 93.8 \%$ and $98.1 \%$ respectively which proves that the method is capable to quantify the analyte accurately and results will be reliable even at trace level.

\section{Ruggedness study}

The intra-laboratory tested behavior of an analytical process when small changes in the environment and/or operating condition are made. The ruggedness of the method was evaluated by estimating \% RSD of derivatized DMS standard solution tested by two different analysts on different days. Validation batches were prepared by each analyst separately. \% RSD of area of DMS peak in standard solutions of both analysts should not be more than $10 \%$. Six replicates of diluted standard solution were injected by each analyst. Relative standard deviation of area of dimethyl sulfate was found $1.02 \%$ and $5.06 \%$ on two different days. Content of dimethyl sulfate in one API batch was tested on two different days and the results were found $1.6 \mathrm{ppm}$ and $1.3 \mathrm{ppm}$ respectively. Method validation summary is given in table 2 .

Table 2: Analytical method validation summary

\begin{tabular}{|c|c|c|c|}
\hline S. No. & Parameter & Acceptance criteria & Results \\
\hline 1 & Selectivity & $\begin{array}{l}\text { DMS derivative peak should be well separated from all known and unknown } \\
\text { impurities of methoxsalen. }\end{array}$ & Method is selective \\
\hline 2 & Solution stability & Report Result & $\begin{array}{l}\text { Solutions are stable up to } \\
24 \mathrm{~h}\end{array}$ \\
\hline 3 & Limit of detection & Report Result & $\begin{array}{l}2.0 \text { ppm wrt test } \\
\text { concentration }\end{array}$ \\
\hline 4 & Limit of quantification & Report Result & $\begin{array}{l}5.0 \text { ppm wrt test } \\
\text { concentration }\end{array}$ \\
\hline 5 & LOQ precision & \%RSD for six replicates of LOQ level standard solutions is NMT: $10.0 \%$ & RSD $5.4 \%$ \\
\hline 6 & Linearity & Correlation: NLT 0.99 & $\mathrm{R}^{2} 0.999$ \\
\hline 7 & Accuracy & $\begin{array}{l}\text { Recovery should be between } \\
80 \% \text { to } 120 \%\end{array}$ & $98.1 \%$ to $104.5 \%$ \\
\hline 8 & Method precision & $\%$ RSD for results of six standard replicate is NMT: $10 \%$ & RSD $1.02 \%$ \\
\hline 9 & Intermediate precision & $\begin{array}{l}\text { \%RSD for results of twelve standard replicate (Method precision and } \\
\text { Intermediate precision) is NMT: } 10 \%\end{array}$ & RSD 3.5\% \\
\hline
\end{tabular}

Abbreviations: DMS is a dimethyl sulphate, $\mathrm{h}$ is hour, ppm is parts per million, wrt is with respect to, \%RSD is percent relative standard deviation, LOQ is limit of quantification, NMT is not more than, NLT is not less than and $\mathrm{R}^{2}$ is correlation coefficient. 


\section{DISCUSSION}

Dimethyl sulfate is used in the manufacturing process of methoxsalen. Since the dimethyl sulfate is known mutagenic and carcinogenic impurity it should not be detected in the medicinal product. As per ICH guideline the allowable intake of dimethyl sulfate is calculated considering maximum daily dose of methoxsalen. So the limit of dimethyl sulfate was found $21.4 \mathrm{ppm}$. Literature reveals that detection and quantification of DMS is possible with highly sophisticated techniques like GCMS which require skilled manpower and maintenance cost is also high. Derivatization techniques also reported but either specific detector were required along with LC or GC or many limitations during analysis were observed due to unstable formation of DMS derivative. The derivative complex is unstable in solution form. In this method the complex formed during pre-column derivatization i.e. anisole, after reacting with phenol is very stable. So fresh or immediate testing of the derivatized product was not required. To make the stable complex, first phenol was reacted with sodium which gives sodium phenoxide and this is used as diluent for preparation blank, standard, test and all other solutions for validation study. Sodium phenoxide is quite stable at room temperature that is later on reacting with DMS to form stable anisole. Solution stability was checked and found that the DMS derivative is stable till twenty-six hours. The stability of the derivatized complex is further confirmed during method validation recovery study. It was performed at three different levels from LOQ to $150 \%$, and recovery was observed minimum $98.1 \%$ and maximum $104.5 \%$ which proves that the derivatized complex is very stable and quantifiable at such a trace level. The method was so sensitive that it could detect the analyte even at $2 \mathrm{ppm}$ and can be quantified at $5 \mathrm{ppm}$ which sufficient and very low level compared to the limit of the DMS genotoxic impurity. Linearity study indicated that area was directly proportional to concentration of the derivatized analyte with $\mathrm{R}^{2} 0.999$ in the concentration range of LOQ to $150 \%$ level with respect to the limit of the analyte. The method was further challenged with inter and intralaboratory changes in operation parameters which are possible during routine day to day testing as well as during technology transfer to another laboratory. Precision of the results was confirmed by performing the testing on different days and two different analysts with separate instruments and found that relative standard deviation was less than $10 \%$ that is the indication of reproducibility of the method at given laboratory conditions. Further, the method was successfully applied to three methoxsalen validation batches with dimethyl sulfate concentration levels were found far below the LOQ.

\section{CONCLUSION}

In conclusion, quantification method was developed to check genotoxic process impurity dimethyl sulfate in methoxsalen drug substance. The proposed method was validated as per ICH guideline and checked accuracy and reliability of the result. The static head space GC-FID analytical method with pre-column derivatization satisfies all validation parameters like system suitability, precision, specificity, accuracy, linearity of detector response, ruggedness and robustness. It indicates that the method is stable and suitable for the quantification of dimethyl sulfate in methoxsalen. Hence, the validated method can be used for routine analysis of quantification of dimethyl sulfate in methoxsalen in quality control laboratories in the pharmaceutical industry.

\section{ACKNOWLEDGEMENT}

Thanks to the management of Wanbury Limited for constant support.

\section{AUTHORS CONTRIBUTIONS}

All authors contribute equally to this manuscript

\section{CONFLICT OF INTERESTS}

Author Ajit Anerao, Bhushan Patil and Nitin Pradhan declare that they have no conflict of interest.

Ethical approval: This article does not contain any studies with human participants or animals performed by any of the authors.

\section{REFERENCES}

1. Rx List. Uvadex. Methoxsalen. 2016; Available from: http://www.rxlist.com/uvadex-drug.htm. [Last accessed on 01 May 2018]

2. United State Pharmacopoeia. Methoxsalen official monograph. USP 40; 2016. p. 5087-8.

3. Shenoi S, Prabhu S. Photochemotherapy (PUVA) in psoriasis and vitiligo. Indian J Derm Vene Leprol 2014;80:497-504.

4. Parrish J, Fitzpatrick T, Tanenbaum L, Pathak M. Photochemotherapy of psoriasis with oral methoxsalen and longwave ultraviolet light. New Engl J Med 1974;291:1207-11.

5. Melski J, Tanenbaum L, Parrish J, Fitzpatrick T, Bleich H. Oral methoxsalen photochemo therapy for the treatment of psoriasis: a cooperative clinical trial. J Invest Derm 1977;68:328-35.

6. IARC. Some pharmaceutical drugs. IARC Monogr Eval Carcinog Risk Chem Hum 1980;24:1-337.

7. IARC. Genetic and related effects. An updating of selected IARC monographs from Volumes 1 to 42. IARC Monogr Eval Carcinog Risks Hum Suppl 1987;6b:1-729.

8. IARC. Overall evaluations of carcinogenicity. An updating of IARC Monographs volumes 1 to 42. IARC Monogr Eval Carcinog Risks Hum Suppl. 1987;7a:1-440.

9. ICH. M7(R1) Addendum to ICH M7. Assessment and Control of DNA Reactive (Mutagenic) Impurities in Pharmaceuticals to Limit Potential Carcinogenic Risk; Application of the Principles of the ICH M7 Guidance to Calculation of Compound-Specific Acceptable Intakes. ICH Harmon Guid; 2017.

10. ICH. Impurities in new drug substances Q3A (R2); 2006.

11. FDA. U. S. Dept of Health and Human Services Food and Drug Adm. Guidance for Industry ANDAs: Impurities in Drug Substances; 2009.

12. Drugs. com. Methoxsalen dosage; 2016. Available from: https://www.drugs.com/dosage/methoxsalen.html. [Last accessed on 01 May 2018].

13. NIOSH. Manual of Analytical Methods (NMAM). Fourth Edition. DIMETHYL SULFATE. METHOD 2524; 1994. Available from: https://www.cdc.gov/niosh/docs/2003-154/pdfs/2524.pdf. [Last accessed on 01 May 2018]

14. FEAIIG. Federation of the Employment Accidents Insurance Institutions of Germany. Centre for Accident Prevention and Occu Med. Method for the determination of dimethyl sulfate (DMS). Ana Met Air Monit Met 1997;5:75-105. Available from: http://onlinelibrary.wiley.com/doi/10.1002/3527600418.am $7778 \mathrm{e} 0005 /$ pdf. [Last accessed on 01 May 2018]

15. Prabhu P. Trace level determination of residues of dimethyl sulfate and diethyl sulfate in pharmaceutical products by headspace gas chromatography and mass spectrometry following derivatization with pentafluorobenzenethiol. Experimental Notes Perkin Elmer; 2015. Available from: http://www.perkinelmer.com/ CMSResources/Images/20130104_8-Trace-level-determination-residues of dimethyl sulfate.pdf. [Last accessed on 01 May 2018]

16. Zheng J, Wayne A, Zhang S, Wittenberger S. Determination of low ppm levels of dimethyl sulfate in an aqueous soluble API intermediate using liquid-liquid extraction and GC-MS. J Pharma Biomed Anal 2009;50:1054-9.

17. Nalavade A, Sandhyakumari B, Ramakrishna K, Srinivasarao V. Development and evaluation of class-1 solvent 1, 2dichloroethane and dimethyl sulphate as a genotoxic impurity in sildenafil citrate drug substance by using GC-MS technique. Int J Pharm Pharma Sci 2014;6;552-5.

18. Schäfer C, Zöllner P. Determination of trace levels of dimethyl sulfate in the presence of monomethyl sulfate by gas chromatography-mass spectrometry. J Chrom A 2013;4:10.

19. Rahman M, Gullick D, Hoerner J, Bartlett M. Determination of genotoxic impurities monomethyl sulfate and dimethyl sulfate in active pharmaceutical ingredients. Anal Methods 2017;7:1112-8.

20. Nanduri V, Reddy K, Adapa V, Ramakrishna K. Validated chromatographic methods for the determination of process related toxic impurities in pantoprazole sodium. Chromatographia 2008;68:481-4.

21. Narendrakumar M, Krishna Reddy V, Sharma H, Kaleemullah T, Madhava Reddy $\mathrm{P}$, John $\mathrm{P}$, et al. Simple and sensitive ion 
chromatography method for the simultaneous determination of dimethyl sulfate and diethyl sulfate contents in metoprolol tartrate drug substance. Chem Sin 2011;2:164-72.

22. ICH. Validation of analytical procedures: Text and methodology Q2 (R1); 2005.
23. Hiers G, Hager F. Anisole. Org Syn 1941;1;58;9;1929;12. Doi:10.15227/orgsyn.009.0012

24. Lunn G, Sansone E. Validation of techniques for the destruction of dimethyl sulfate. Am Indu Hyg Assoc J 1985;46:111-4. 